establishing an independent, non-profit drugdevelopment agency to acquire new drugs from private or public entities after they get regulatory approval. The agency would then auction the drug rights to manufacturing firms, who would bid based on prices it set. The auction revenue, supplemented by government funds generated by the lower cost of medicines for the health-care system, would cover the rewards given to R\&D companies. To enforce the separation of the research and manufacturing arms, the authors propose that the agency would refuse applications from companies engaged in drug production.

Finkelstein and Temin argue that their proposal preserves free enterprise. They also tip their hats to Senator Bernie Sanders (Independent, Vermont), the socialist maverick who introduced legislation to establish a prize fund to spur drug innovation. They claim their scheme is better because of its auction component, but like Sanders they propose to replace exclusive marketing rights derived from patent monopolies with a prize system. The real innovation is their insistence on also changing the pharmaceutical industry's structure.

The authors should have spent more time wrestling with the finer points of their proposal instead of dwelling on the failures of the current system. For instance, to determine research priorities and set prize levels once market failure has been ushered off stage, their solution is to give the task to multidisciplinary committees set up by the new drug-development agency, which they compare with the grant-approval sections of the National Institutes of Health. The work would be peer-reviewed by groups such as the National Academy of Sciences or the US Pharmacopeia, a 188-year-old nonprofit organization responsible for establishing formularies as part of the Medicare Prescription Drug, Improvement and Modernization Act of 2003. It added a prescription-drug benefit to Medicare, the US health-care programme for senior citizens.

This solution is curious given that Finkelstein, as revealed in the book, sat on the US Pharmacopeia-Medicare committee that set formularies under the act; drug firms successfully lobbied to influence the committee's decisions. It is unlikely to be any different when a panel is determining, for example, the relative value of a cure for Alzheimer's disease versus an incremental advance in treating dyspepsia. In the end, the perceived values of such cures determine the willingness of the private sector to pour resources into the hunt.

These quibbles could be thrashed out in the legislative arena if the book's ideas ever gain traction. The hard facts remain: drug prices are unsustainably high, new drug approvals are declining, and promising approaches are being ignored. By suggesting a way for publichealth objectives to drive private biomedical research investment, Finkelstein and Temin offer the drug industry a path out of its current predicament.

Merrill Goozner is at the Center for Science in the Public Interest, 1875 Connecticut Avenue NW, Washington DC 20009, USA. He is author of The $\$ 800$ Million Pill and writes at www.gooznews.com.

See Editorial, page 823 and online at http://tinyurl.com/3tt3y3.

\title{
Complementary cures tested
}

Trick or Treatment? Alternative Medicine
on Trial
by Simon Singh and Edzard Ernst
Random House/Norton: 2008.352 pp.
$€ 16.99 / \$ 25.95$

The international market for alternative therapies is estimated at US $\$ 40$ billion. Because so many people use alternative medicine, it provides an excellent vehicle for discussing the nature of scientific research. Yet explaining the evaluation of evidence, balance of probabilities and risk is not easy.

Combining their communication skills and knowledge, writer Simon Singh and professor of complementary medicine Edzard Ernst set out for the lay person the scientific approach to testing alternative medical treatments. Trick or Treatment? starts by detailing the development and evolution of the double-blind, placebo-controlled, randomized controlled trial and its role in evidence-based medicine. The authors evaluate the evidence for four common alternative therapies acupuncture, homeopathy, herbal medicine and chiropractic. They discuss the pitfalls of placebo-based medicine and ask who is to be blamed for spreading misinformation about unproven treatments. The book concludes with a manifesto for better regulation of alternative medicine and reliance on properly tested therapies.

Trick or Treatment? is thor oughly researched and clearly written. Historical descriptions sit beside detailed and lucid evaluations of the research evidence. Some stories are well known, such as how naval surgeon James Lind developed the first clinical trial to test the effectiveness of lemons for treating scurvy. Others are less familiar, such as

Florence Nightingale's aptitude for statistics and her development of a variant of the pie chart, the polar area chart, to support the case that good sanitation dramatically reduced deaths in military hospitals. The description of the Nazis' adoption of homeopathy is particularly compelling and sobering. These tales make the book entertaining as well as informative.

In the discussions of the four therapies, the authors' combined strengths shine through. The examination of the evidence is comprehensive, forensic and, for champions of these therapies, damning. For each treatment, Singh and Ernst present the available randomized controlled trials. They describe and dissect good-quality evidence and dismiss the poorquality stuff, giving their reasons why it should

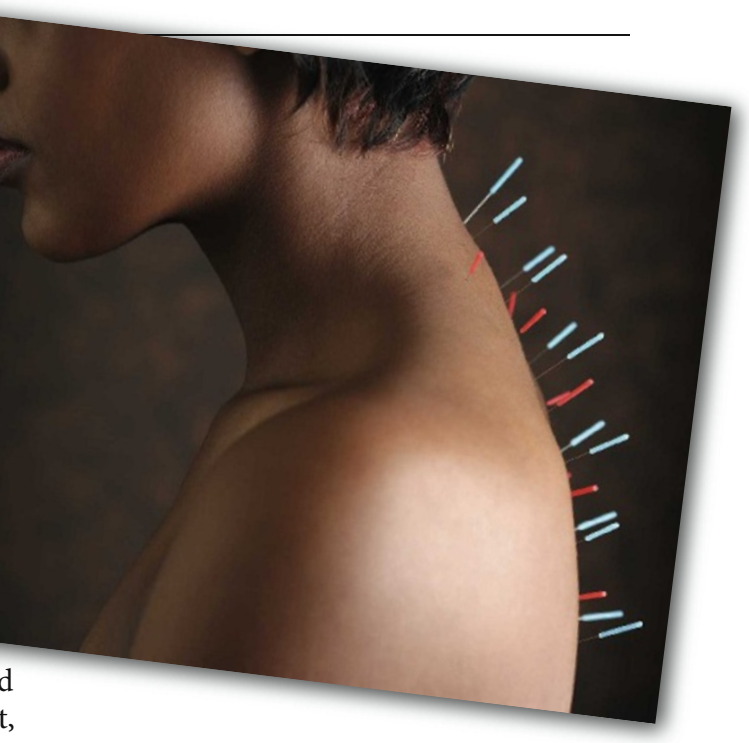

Acupuncture: pain relief or placebo?

be discounted. The authors conclude that acupuncture works as a short-term analgesic and can relieve nausea but not much else; that some herbs such as Devil's Claw for musculoskeletal pain or garlic for high cholesterol are effective; chiropractic can improve back pain but less well than conventional treatments; and that homeopathy is no better than placebo. They summarize evidence for a further 30 therapies, most of which they find wanting.

Singh and Ernst base their evaluations solely on results from randomized controlled trials. Many advocates of alternative treatments argue 
that these trials are unsuitable. Some of these practitioners' arguments are easily dismissed, for example, the idea that alternative treatments are beyond science. Other criticisms come from respectable commentators and are harder to ignore; for instance, the difficulties of designing trials to investigate complex treatments with multiple variables, or whether these trials use test conditions that differ from a treatment as practised. Randomized controlled trials are powerful tools, but they are imperfect and it would have strengthened the argument of Trick or Treatment? had the book discussed these downsides.

Scientific research is intrinsically provisional; it may asymptotically approach a truth, but it is never unequivocal. Singh and Ernst, however, make repeated claims that they provide the truth, and have even included this word in the title of every chapter. The balance of evidence from randomized controlled trials supports their arguments, but the authors are not tendering a disprovable hypothesis. Many science communicators argue that to present science as the only truth does it a disservice. For now, the certainty expressed in Trick or Treatment? mirrors that of the proponents of alternative therapies, leaving each position as entrenched as ever.

Toby Murcott is a freelance science writer and broadcaster based in the UK. He is author of The Whole Story: Alternative Medicine on Trial?

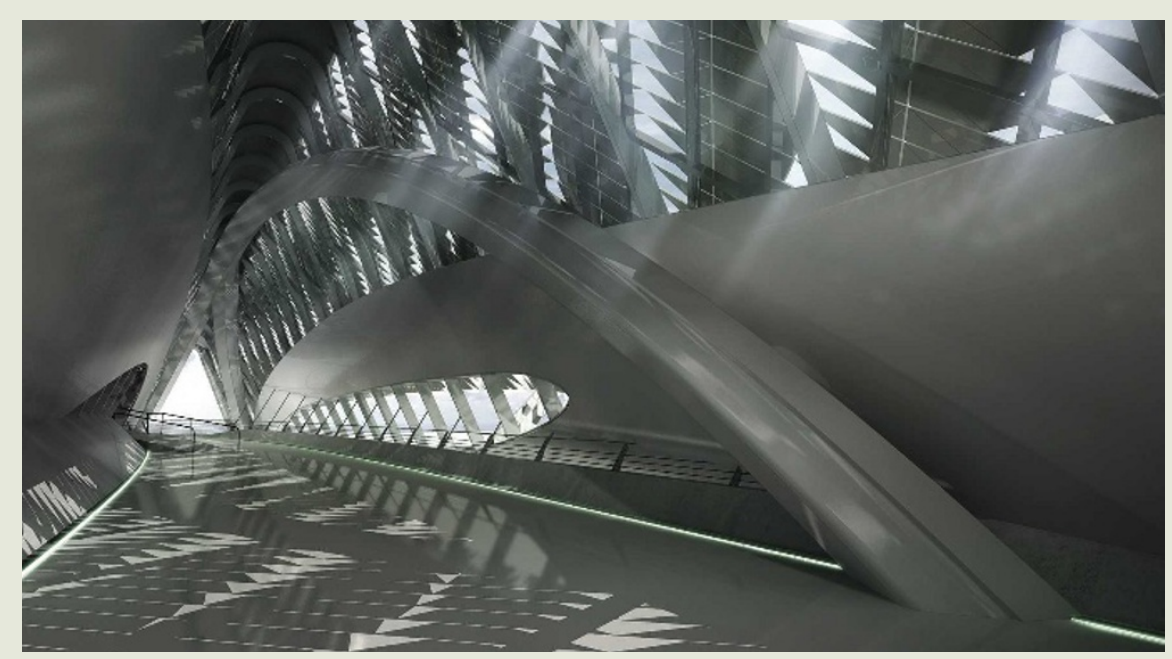

\section{Saving water}

Water and sustainable development is the theme of Expo Zaragoza 2008, a biennial international festival of culture to be held in Saragossa, Spain, from 14 June to 14 September. Inside a meander of the river Ebro, a park has been built displaying ecological materials, renewable energy and sustainable water management. The festival's 140 pavilions - including architect Zaha Hadid's sinuous bridge (pictured), clad in steel scales that mimic shark skin, and a glass tower shaped like a water droplet - will house exhibitions and events.

A platform for technical, scientific and social debate, the Expo will host nine weeks of themed seminars on water conservation, climate change and development. A series of essays has been commissioned by the Expo from global figures, including ex-president of the former Soviet Union Mikhail Gorbachev, EU High Representative Javier Solana and Nobel Peace prize winners Rigoberta Menchú and Wangari Maathai. www.expozaragoza2008.es

\section{Suppressing science}

\section{Doubt Is Their Product: How Industry's Assault on Science Threatens Your Health by David Michaels \\ Oxford University Press: 2008. 384 pp. $\$ 27.95, \notin 14.99$}

David Michaels has written a powerful, thorough indictment of the way big business has ignored, suppressed or distorted vital scientific evidence to the detriment of the public's health. Doubt Is Their Product catalogues numerous corporate misdemeanours, especially in the United States, from the criminal neglect of the dangerous nature of asbestos and the lies told by the tobacco industry, to the suppression of adverse findings of deaths caused by the anti-inflammatory drug Vioxx and the increased risk of suicide among teenagers taking selective serotonin re-uptake inhibitors for depression. The book concludes with a list of prescriptions for securing better regulation and greater protection for the public, mainly through increased public disclosure of vested interests.

The central question Michaels raises is whether our dependence on corporate funding in Western society can be reconciled with the integrity of scientific research and, if so, how. It can be argued that the importance of the motivation of a company or a scientist tends to be exaggerated. Our present system contains a strong element of self-regulation through self-interest. Companies make profits by manufacturing successful products that are useful to the public, and are damaged if their products are shown to be ineffective or harmful. They may face ruin if they cause disaster, as in the case of thalidomide. From time to time they err, but regulation keeps aberrations to a minimum. Big pharmaceutical companies, for example, have served public interest by producing a stream of drugs that has greatly improved the quality and length of our lives, as Michaels acknowledges.

Individual scientists have reason to avoid dishonesty and incentives to ensure that their research stands up to scrutiny. Their reputations - and careers - depend on doing good science and suffer if findings are discredited. Corporate research is peer reviewed and results are accepted only when shown to be reproducible. Whatever its limitations, peer review is the best guarantee we have of research quality. These incentives and safeguards apply whether scientists work for companies, universities or the government. If the science is good, it survives; if not, it does not, whatever the funding source or the scientist's personal motive.

Yet, as Michaels demonstrates, motivation cannot be ignored. Canadian scientists examined papers on the controversial question of whether calcium-channel blockers used to treat high blood pressure increased the risk of heart attack. They found that, of those who supported the use of such blockers, $96 \%$ had a financial connection with the manufacturers. This compared with $60 \%$ of those who were neutral and $37 \%$ of those who were critical. Many studies of other drugs have found similar correlations between sponsorship and conclusions. 